Dept. Anatomy \& Histology,

Faculty of Vet. Med., Alexandria University,

Head of Dept. Prof. Dr. A. Kassem.

\title{
ANATOMICAL STUDIES ON THE MUSCLES OF THE LEG REGION IN THE ONE HUMPED CAMEL (CAMELUS DROMEDARIUS), REGARDING THE COURSE AND THE RELATIONS OF THEIR TENDONS (With 7 Figs.)
}

$$
\begin{aligned}
& \text { By } \\
& \text { A.K. HEMMODA; A.A. KARKOURA; E.I. ENANY; } \\
& \text { M. AMIN AND R. EL-BAKARY } \\
& \text { (Received at 8/6/1991) }
\end{aligned}
$$

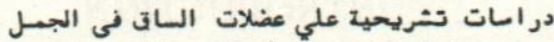

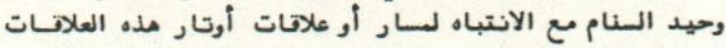

$$
\begin{aligned}
& \text { عبد السلام حمودة ، أشرف ترقورة ، السيد عناني ، محسد أميـن } \\
& \text { رأفت البقري }
\end{aligned}
$$

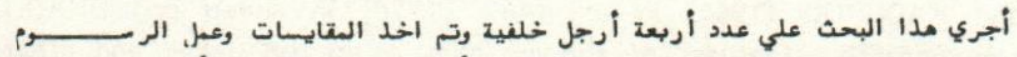

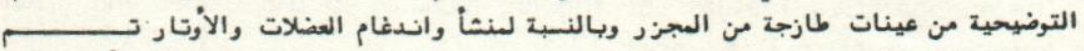

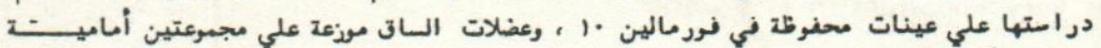

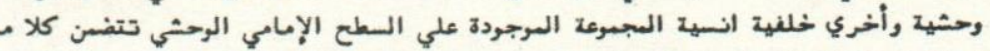

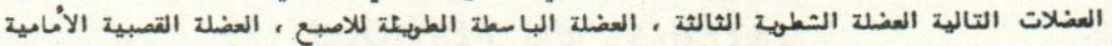

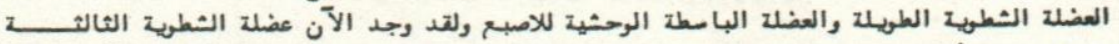

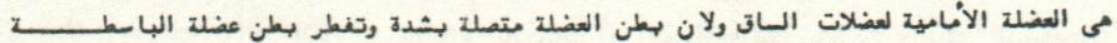

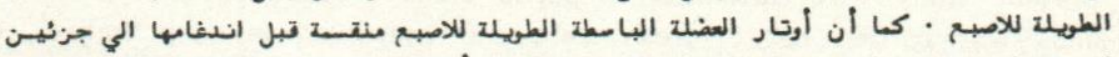

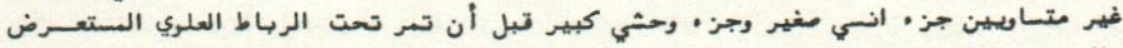

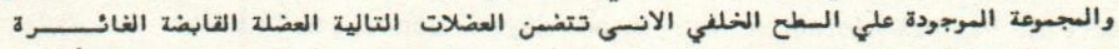

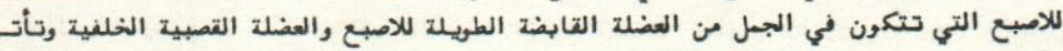

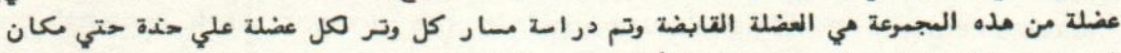

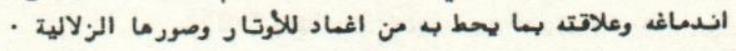

\section{SUMMARY}

The muscles of the leg region consist of craniolateral group and caudomedial group. The former group includes Mm.peroneus (Fibularis) tertius, extensor digitorum longus, tibialis cranialis, peroneus longus and extensor digitorum lateralis. The M.fibularis tertius is the most cranial muscle of

Assiut Vet.Med.L, Vol. 26, No. 51, October 1991. 


\section{A.K. HEMMODA, et al.}

the leg and its fleshy belly is firmly attached and overlapping the fleshy part of the M.extensor digitorum longus.

The tendon of insertion of the extensor digitorum longus is divided into two unequal parts, small medial and large lateral one, before passing under the proximal tarsal retinaculum.

The M.peroneus longus of the camel which is grossly fleshy, comes from the lateral tibial condyle.

The caudomedial group includes, Mm.flexor digitorum profundus and popliteus. The M.flexor digitorum profundus consists of Mm.flexor digitorum longus and tibialis caudalis only.

\section{INTRODUCTION}

The descriptive studies on the origin, insertion, structure, relation and measurements of the craniolateral and caudomedial groups of the muscles of the leg were rarely applied in the dromedary only by SMUTS and BEZUIDENHOUT (1987) in the recent time. But in the other domestic animals many text-books were carried out RAGHAVAN and KACHROO (1964) in ox, MAY (1970) in sheep and BRADLEY (1946) in horse. The comparative features of the leg muscles in the camel and other domestic animals is very important in this work.

\section{MATERIAL and METHODS}

The present study was carried on 4 pelvic limbs of the dromedary, the dissection of two limbs was carried out in fresh state and preserved in deep freezer, and the other two limbs were injected by $10 \%$ formalin solution through the external iliac artery and preserved in $10 \%$ formalin for three days, then dissected for the determination of the origin and insertion, the fresh samples also used in taking all the muscle and tendons measurements. The nomenclature used in the present work as what mentioned by the Nomina Anatomica Veterinaria (1983).

\section{RESULTS}

\section{1 - Craniolateral group:}

It consists of five muscles.

Assiut Vet.Med.l, Vol. 26, No. 51, October 1991. 


\section{MUSCLES OF THE LEG IN CAMEL}

\section{a) M.Peroneus (fibularis) tertius (1, 2, 4, 6/1):}

It is the most cranial nuscle of the leg, it originates by a strong common tendon together with the M.extensor digitorum longus, this common tendon which has $10 \mathrm{~cm}$ length and $1.5 \mathrm{~cm}$ thickness, is attached to the extensor fossa of the femur.

The belly of this muscle is firmely attached with the fleshy part of the M.extensor digitorum longus $(1,2 / 2)$ at the proximal third of the crus region and somewhat difficult to be separated. The shape is fusiform flattened craniocaudally where it overlaping the M.extensor digitorum longus. The length of this fleshy part is about $28 \mathrm{~cm}$ and has $6 \mathrm{~cm}$ width.

The tendon of insertion of this muscle $(1,2,4 / 9)$ is the thickest and strongest one among the tendons of this group. It start at about $10 \mathrm{~cm}$ proximal to the hock joint, where it is surrounded by the proximal tarsal retinaculum $(4 / f)$ in common with the tendon of Mm.tibialis cranialis and extensor digitorum longus and sheathed also together by a common dorsal tendon sheath $(5 c / 23)$. At the level of the tarsocrural joint the tendon of insertion divided into two branches (6/9), dorsal and lateral one. The former is attached to the metatarsal tuberosity while the latter is thiner crossing the tendon of the M.extensor digitorum longus tobe attached in the second and third tarsal bone together with the distal tarsal retinaculum.

\section{b ) M.extensor digitorum longus (1, 2, 6/2):}

It originates by a common tendon with M.peroneous tertius in the extensor fossa of the femur. Its fleshy part is elongated with $22 \mathrm{~cm}$ length and $3-5 \mathrm{~cm}$ thickness, it is partially attached with the distal fleshy part of the M.peroneous tertius. The fleshy part of this muscle is partially covered by the later muscle, so it can be observed only laterally at the level of the middle third of the leg.

The tendon of insertion of this muscle $(1,2,6 / 10)$ is divided into two unequal parts, small medial and large lateral large $(5 c, 6 / 10)$, which are located lateral to the tendon of M.peroneus tertius and also surrounded together with the M.tibialis cranialis by the proximal tarsal retinaculum as well as sheathed together by the common dorsal tendon sheath.

Distal to the level of tarsal joint the two tendons of this muscle pass under the distal tarsal retinaculum, then the medial tendon extends as the proper extensor tendon of the third digit on the medial aspect of the metatarsus $(6 / 29)$ toward the abaxial part of the dorsal aspect of the metatarso phalangeal joint of the third digit. Here it receives a band from the abaxial slip of the M.interoseous medius to be inserted on the dorsal abaxial aspect of the fibrous joint capsule of the pastern joint of the third digit and also proximal to this, it attached in the dorsal axial aspect of the fibrous joint capsule of the fetlock joint of the same digit.

Assiut Vet.Med.l, Vol. 26, Na. 51, October 1991. 


\section{A.K. HEMMODA, et al.}

The lateral tendon courses on the lateral aspect of the metatarsus between the medial tendon medially and tendon of M.extensor digitorum lateralis laterally. As it reaches the intertrochlear notch of the metatarsus, where it divides into two branches, the common digital extensor tendons $(6 / 30)$ which directed toward the digits, each of which after about $5 \mathrm{~cm}$ from the notch is divided into long and short branch. The latter receives a band from the corresponding axial slip $(6 / 25)$ of the M.interosseous medius and inserted in the dorsal fibrous joint capsule of pastern joint. The long branches courses distally on the corresponding digit towards its insertion on the extensor process of the third phalanx.

\section{c) M.tibialis cranialis $(1,2,4 / 3)$ :}

It is the smallest and deepest muscle of this group. It originates from the lateral tibial condyle, the extensor groove of tibia and lateral part of the tibial tuberosity by a fleshy attachement. The belly rests completely on the lateral surface of the tibia partially undercover of the M.peroneus tertius, so the cranial fleshy part of this muscle can be observed only lateral to the tibial crest. The length of the fleshy part is about $20 \mathrm{~cm}$ and the thickness is $1 \mathrm{~cm}$. It has a long tendon of insertion which is (1, 2, $4 / 11$ ) about $25 \mathrm{~cm}$ continues its course distally between the tibia medially and the peroneus tertius laterally where it covered by the proximal tarsal retinaculum together with the tendons of Mm.peroneus tertius and extensor digitorum longus with their common tendon sheath, to be inserted after, in the first and the fused second and third tarsal bones.

\section{d) M.peroneus longus (1, 2, 3/4):}

This muscles is located caudolateral to the Mm.peroneus tertius and extensor digitorum longus. Its belly is triangular in outline with elongated apex directed distally. It originates by a fleshy origin from the lateral tibial condyle. The fleshy part is about $21 \mathrm{~cm}$ length, $1.5 \mathrm{~cm}$ thickness.

The tendon of insertion $(1,2,3,5 a / 12)$ begins at the middle of the leg. It continues its course distally on the malleolus where it covers and crosses the tendon of the M.extensor digitorum lateralis $(1,2,3,5 a / 13)$ and are surrounded together by a common tendon sheath $(5 a / 22)$. Then it courses distally and plantarly in a groove on the fourth farsal bone undercover of the lateral collateral ligament of the tarsal joint $(5 a / 8)$ to be inserted in the first tarsal bone. The whole length of the tendon of insertion of this muscle about $30 \mathrm{~cm}$.

\section{e ) M.extensor digitorum lateralis (1, 2, 3/5):}

It is the most lateral muscle flattened craniocaudally. It originates by a fleshy part caudal to the origin of M.peroneus longus in the lateral tibial condyle and the lateral border of the tibiaalong its fleshy part. 


\section{MUSCLES OF THE LEG IN CAMEL}

The fleshy part of this muscle is situated between M.peroneus longus cranially $(2 / 4)$ and M.flexor digitorum longus caudally (2/6). The length of this muscle is 22 $\mathrm{cm}$ and it has $2 \mathrm{~cm}$ thickness.

The tendon of insertion (1, 2, 3, 5a/13) continues its course distally in common with the tendon of M.peroneus longus but situated caudal to the latter on the lateral border of the tibia. Both of these tendons change its direction after passing in the groove on the lateral malleolus of the tibia. The tendon of M.peroneus longus covering and crossing the tendon of M.extensor digitorum lateralis to be located plantarly in the tarsal region. While the tendon of M.extensor digitorum lateralis directed dorsally on the tarsal region then continue its course distally to become lateral to the tendon of M.extensor digitorum longus. Then it descends dorsolaterally on the metatarsus $(6 / 13)$ to be attached to the dorsal aspect of the capsule of the fetlock joint of the fourth digit. At this level it recieves a band from the abaxial slip of the M.interosseous medius. The tendon continue its course also to be inserted finally in the dorsal aspect of the distal end of the proximal phalanx.

\section{II - Caudal group of the leg:}

\section{a ) M.flexor digitorum profundus:}

It consists of two heads onlys, one is small called M.flexor digitorum longus and the second is larger which repreents the M.tibialis caudalis as it completely fused with the M.flexor digiti I longus so it seems as it is one single muscle.

1 - M.flexor digitorum longus $(2,3,4 / 6)$ :

It is located caudolaterally between the M.extensor digitorum lateralis laterally and the M.tibialis caudalis, medially and the M.poploteus proximally.

It originates from the caudal part of the lateral tibial condyle and the proximal part of the lateral border of the tibia by a fleshy origin. The length of the fleshy part is about $25 \mathrm{~cm}$ and its thickness is $2.5 \mathrm{~cm}$.

The length of its tendon from the fleshy part till the union with the tendon of insertion of the M.tibialis caudalis is about $24 \mathrm{~cm}$, and has $1 \mathrm{~cm}$ width $(2,3,4,5 \mathrm{~b} / 14)$. It is surrounded by a tendon sheath of about $12 \mathrm{~cm}$ length $(5 \mathrm{~b} / 21)$ during its passage on the caudal surface of the distal third of the tibia toward the medioplantar aspect of tarsus to unite with the M.tibialis caudalis just at the level of tarsometatarsal joint.

2 - M.tibialis caudalis $(2,3,4 / 7)$ :

It is the largest muscle of the deep digital flexor muscle. It is represented by both muscles (Mm.tibialis causalis and flexor digiti I longus) which can not be separated and seems as one muscle. It originates from the caudal part of the iateral tibial condyle, lateral border of the tibia and caudal surface of the proximal two thirds of the tibia. The length of the fleshy part is $27 \mathrm{~cm}$ and has $4 \mathrm{~cm}$ thickness.

Assiut Vet_Med.l, Vol. 26, No. 51, October 1991. 


\section{A.K. HEMMODA, et alo}

The length of the tendon of insertion $(3,4,5 b / 15)$ from the fleshy part till its union with the tendon of M.flexor digtorum longus $23 \mathrm{~cm}$ and has $1.5 \mathrm{~cm}$ width. Then it continues its course distally on the tibia where it passes on a subtendinous bursa $(1.5 \times 3.0 \mathrm{~cm})$ between it and the caudal part of the medial malleolus $(5 \mathrm{~b} / 19)$. It is directed plantarly to unite with the tendon of the M.flexor digitorum longus and together they pass distalward undercover the distal plantar tarsal retinaculum to form the common tendon of M.deep digital flexor.

The union of both tendons of th latter two muscles occures nearly at the plantar aspect of the tarsometatarsal joint where it is surrounded by a tendon sheath $(5 \mathrm{~b} / 20)$ of about $6 \mathrm{~cm}$ length. The common tendon continues its course distally and plantarly to the metatarsus till the intertrochlear notch where it divided into two branches undecover the tendon of the M.flexor digitorum superficialis $(5 a, b, 7 b / 16)$ one for each digit to be inserted finally in the plantar surface of the third phalanx. There is a common plantar digital tendon sheath $(7 \mathrm{~b} / 28)$ for both tendons of M.flexor digitorum superficialis \& profundus which begins just distal to the bifurcation of the tendons by about $5 \mathrm{~cm}$ and extends distally till the coffin joint.

b) M.Poploteus, (2, 3, 4/8):

It is a triangular muscle, its apex has a well developed tendon of origin (its length $6 \mathrm{~cm}$ and has $1.5 \mathrm{~cm}$ thickness) which is attached to the poploteal fossa on the femur. This tendon is surrounded by a recess from the femorotibial joint sac and separating it from the lateral meniscus.

The insertion of this muscle in the caudal part of the medial and lateral condyles of the tibia, the medial border of the proximal third of the tibia and the remained part of the proximal third of the tibia as well as the intermuscular septa between it and the M.flexor digitorum profundus.

\section{DISCUSSION}

The leg region of the camel has two groups of muscles, the most cranial and superficial muscle of them is the M.peroneus tertius as observed in the present work as also recorded by SMUTS and BEZUIDENHOUT (1987) in camel, DELAHUNTA and HABEL (1986), RAGHAVAN and KACHROO (1964) in ox as well as POPESKO (1968), GETTY (1975) and NICKEL, SCHUMMER and SEIFERLE (1986) in large and small ruminants. While DELAHUNTA and HABEL (1986) added that the M.extensor digitorum longus in horse and M.tibialis cranialis in the dog is the superficial and most cranial muscles, the results which is confirmed Similarly by BRADLEY (1946) and SISSON (1975) in euine and by MILLER (1964) in dog as well as CROUCH (1969) in cat.

Assiut Vet.Med.J, Vol. 26, No. 51, October 1991. 


\section{MUSCLES OF THE LEG IN CAMEL}

The M.peroneus tertius originate from the extensor fossa. Its belly is attached proximally with the M.extensor digitorum longus. It is inserted in two parts only, in the metatarsal tuberosity and the second and third tarsal bone together with the distal tarsal retinatiaculum. SMUTS and BEZUIDENHOUT (1987) in the camel recorded that the tendon of insertion of this muscle splits into three parts the results which were not observed in this work MORCOS (1955) in camel said that it inserted in the third tarsal and third metatarsus. BRADLEY (1946) and SISSON (1975) in equine said that it is tendinous completely and fused with M.tibialis cranialis, the insertion of this muscle takes police by three limbs of division. On the other hand MILLER (1964) in dog and CROUCH (1969) in cat mentioned that the craniolateral group of muscles of the leg are Mm.tibialis cranialis, extensor digitorum longus, peroneus longus, extensor digitorum lateralis, and the special muscle extensor hallucis longus, but these authors did not mention the M.peroneus tertius.

The M.extensor digitorumlongus of the present work originate from extensor fossa. Its belly is single laterally located. It gives off two tendons medial for the third digit and lateral one common for both digits. The medial tendon is inserted in the joint capsule of the pastern joint and the lateral one in the extensor process of the third phalanx. These results are similar to that mentioned by SMUTS and BEZUIDENHOUT (1987) in camel, RAGHAVAN and KACHRO (1964) in ox, BERG (1982) in cow and NICKEL, et al. (1986) in ruminants. However, POPESKO (1968) in ruminant, MAY (1970) in sheep and GETTY (1975) in ruminant, in addition to their agreement with present results they confirmed that this muscle is divided into two bellies, the results which were not observed by the present work in the camel where it has one belly.

The M.tibialis cranialis of the present work is the smallest and deepest muscle of its group, has fleshy origin from the tibia and inserted in the first tarsal and fused second and third tarsal the same results observed by MORCOS (1955) and SMUTS and BEZUIDENHOUT (1987) in the camel. The latter auther added that it is inserted in the first tarsal and third metatarsal bones only the results which not observ in this work. RAGHAVAN and KACHROO (1964) in ox, MAY (1970) in sheep and GETTY (1975) in ruminants recorded that this muscle has two heads in its origin and its insertion reach to the large metatarsus, the results which not be observed by the present work.

The M.peroneus longus in the camel of the present work has a fleshy origin from lateral tibial condyle and inserted in the first tarsal bone. These results are similar to that mentioned by SMUTS and BEZUIDENHOUT (1987) in camel and MAY (1970) in sheep. While MCLEOD (1958), RAGHAVAN and KACHROO (1964) in ox, GETTY (1975) and NICKEL, et al. (1986) in ruminant showed similar results and added that it inserted also in the proximal part of the large metatarsus beside the first tarsal bone. Moreover, MCLEOD (1958) in bovine and GETTY (1975) in ruminants added that the origin of this muscle is wide and aponeurotic whereas the origin in this work is grossly fleshy. 


\section{A.K. HEMMODA, et al.}

The M.extensor digitorum lateralis originate from the lateral tibial condyle and courses distally till the distal end of the proximal phalanx, the results which are similar to that mentioned by SMUTS and BEZUIDENHOUR (1987) in the camel. However, the insertion described by MAY (1970) in sheep GETTY (1975) and NICKEL, et al. (1986) in ruminants at the middle phalanx, while RAGHAVAN and KACHROO $\overline{(1964)}$ in ox added that it inserted in dorsal surface of the middle phalanx and lateral surface of the third phalanx. However, MAY (1970) in sheep and GETTY (1975) in ruminants recorded that the origin of this muscle in addition to the lateral condyle of tibia, is attached to the lateral collateral ligament of the stifle joint.

The M.flexor digitorum profundus in the present work consists of two heads only, M.flexor digitorum longus and the completely fused M.tibialis caudalis with the M.flexor digiti one longus the results which are similar to that observed by SMUTS and BEZUIDENHOUT (1987) in camel. However, MCLEOD (1958) in bovine, RAGHAVAN and KACHROO (1964) in ox, MAY (1970) in sheep, GETTY (1975) and NICKEL, et al. (1986) in ruminants mentioned that the Mm.tibialis caudalis and flexor digiti I lingus are partially separated from the fleshy part and the tendons of insertion are separated at the distal third of the leg and fused again with the tendon of M.flexor digitorum longus at the level of the tarsal region to form one large tendon passing in the tarsal groove.

The M.poploteus of the present work originate from the poploteal fossa and inserted in tibial condyles and proximal third of tibia as what mentioned by SMUTS and BEZUIDENHOUT (1987) in the camel, RAGHAVAN and KACHROO (1964) in ox, MAY (1970) in sheep GETTY (1975) and NICKEL, et al. (1986) in ruminants.

\section{REFERENCES}

Berg, R. (1982): Angewandte und topographische Anatomie der Haustiere. Veb. Gustav. Fischer, Verlag Jena.

Bradley, O. (1946): The topographical anatomy of the limbs of the horse. 2nd Ed. W. Green and Son limited Edinburgh.

Crouch, J.E. (1969): Cat anatomy 1st Ed. Philadelphia, Lea and Febiger.

Delahunta, A. and Habel, R. (1986): Applied veterinary anatomy, chapter .14 , stifle and leg, horse and ox. 1st. W.B. Saunders Company, Philadelphia, London, Mexico City.

Getty, R. (1975): The anatomy of the domestic animals (Ruminant myology) 5th Ed. W.B. Daunders Comp., Philadelphia, London, Toronto.

May, N.D. (1970): The anatomy of the sheep 3rd Ed. University of Queensland press, st. Lucia, Gueensland.

Mcleod, W.M. (1958): Bovine anatomy. 2nd Ed. Burgess Pybl. Co. Minneapolis.

Assiut Vet.Med.1, Vol. 26, No. 51, October 1991. 


\section{MUSCLES OF THE LEG IN CAMEL}

Miller, M.E.; G.C. Christensen and H.E. Evans (1964): Anatomy of the dog. W.B. Saunders Company, Philadelphia.

Morcos, B.M. (1955): The anatomical study of the joints of the camel. Thesis M.D., Fac. Vet. Med., Cairo Univ.

Nickel, R.; Schummer, A. and Seiferle, E. (1986): The locomotor system of the domestic animals (ruminant myology). Vol. I. translated from the 5th Ed. German by W.G. Siller and W.M. stikoe. Verlag paul parey Berlin, Hamburg.

Nomina Anatomical Veterinaria (1983): Published by the International comittee on Vet. Anat. 3rd Ed. Lithaca, New York.

Popesko, P.P. (1968): Atlas of topographical anatomy of the domestic animals. Vol. I, 2nd Ed. Translated by R.Getty W.B. Saunders Co. Philadelphia.

Raghavan, D. and Kachroo, M. (1964): Anatomy of the ox. 1st Ed. Indian Council of Agricultural Research New Delhi.

Sisson, S. (1975): Equine mycology in Sisson and Grossman's the anatomy of domestic animals, Rev. by Getty Sth Ed. W.B. Saunders Company, Philadelphia, London and Toronto.

Smuts, M.M. and A.J. Bezuidenhout (1987): Anatomy of the Dromedary Clarendon press, Oxford. 1st Ed.

\section{LEGEND}

- Diagrams showing the arrangement of the right leg muscles and their tendons.

Fig. (1) Cranial view.

Fig. (2) Lateral view.

Fig. (3) Caudal view.

Fig. (4) Medial view.

- Diagrams showing the course and arrangement of the tendons of the right leg muscles on the tarsus region, with their tendon sheaths and bursae were injected.

Fig. (5) a. Lateral view of tarsus.

Fig. (5) b. Medial view of tarsus.

Fig. (5) c. Dorsal viẹw of tarsus.

- Diagram showing the course and termination of the tendons of the right leg muscles on the pes region.

Fig. (6) Dorsal view.

- Diagram showing the course and relationship as well as the common planter igital tendon sheath of the deep and superficiai digital flexor tendons.

Fig. (7) A. plantar view of digioital region for flexor tendons.

Fig. (7) B. planter view of digital region for the common plantar digital tendon sheath.

Assiut Vet.Med.1, Vol. 26, No. 51, October 1991. 


\section{A.K. HEMMODA, et al.}
a) femur
b) tibia.
c) tarsal joint.
d) stifle joint.
e) calcaneus.
f) proximal extensor retinaculum of tarsus.
g) lateral collateral ligament of tarsal joint.
h) fetlock joint.
i) pastern joint.
j) coffin joint.
k) flexor digital retinaculu.
I) third phalan $x$.

1- M.peroneus tertius. 2- M.extensor digitorum longus.

3- M.tibials cranialis. 4- M.peroneus longus.

5- M.extensor digitorum lateralis.

6- M.flexor digitorum longus.

7- M.tibialis caudalis. 8- M.poploteus.

9- tendon of $1 \quad 10-$ tendon of 2

11 - tendon of 3

12- tendon of 4

13- tendon of $5 \quad 14-$ tendon of 6

15- tendon of $7 \quad 16$ - tendon of superficial digital flexor muscle.

17- tendon of gastrocnemious muscle. 18- calcaneal bursa.

19- bursa under the tendon of M.tibialis caudalis.

20 - common tendon sheath of the deep digital flexor muscles.

21 - tendon sheath of 6.22 - common tendon sheath of both 4 and 5 .

23- common tendon sheath of 1,2 and $3 \quad 23-$ common tendon sheath of 1,2

and 3 .

24- abaxial branch of interosseous medius muscle.

25- axial branch of interosseous medius muscle.

26- tendon of superficvial digital flexor muscle (cutted).

27 - tendon of deep digital flexor muscle.

28- common plantar digital tendon sheath of both superficial and deep digital flexor tendons.

29- proper extensor tendon of gigit III.

30- common digital extensor tendon.

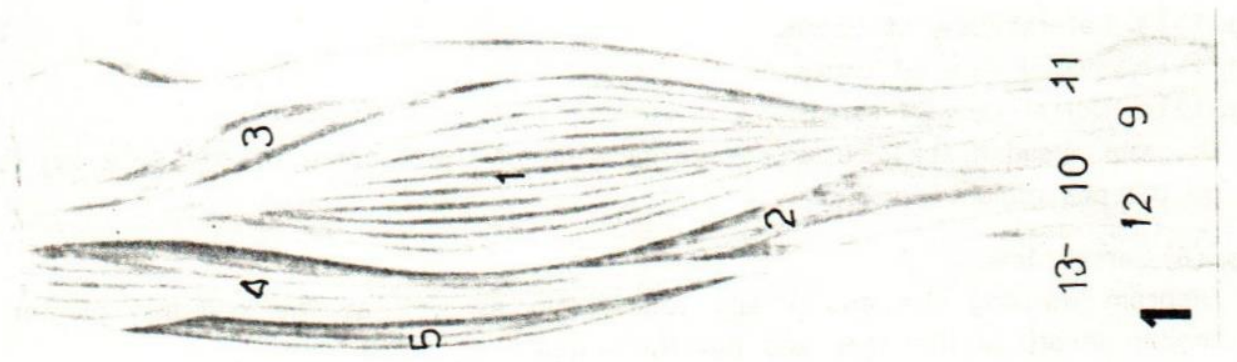

Assiut Vet.Med.1., Vol. 26, No. 51, October 1991. 
MUSCLES OF THE LEG IN CAMEL
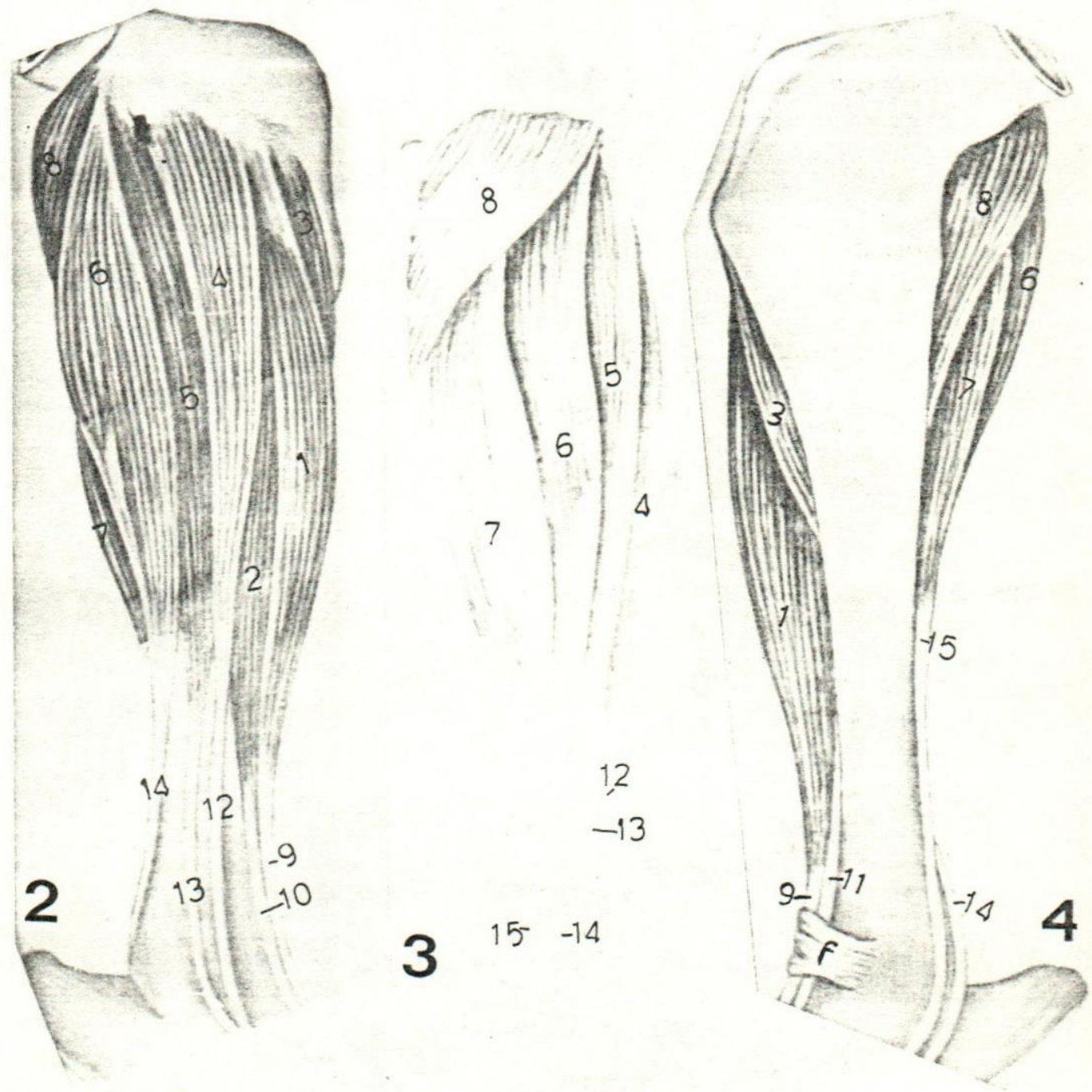

Assiut Vet.Med.J., Vol. 26, No. 51, October 1991. 
A.K. HEMMODA, et al.
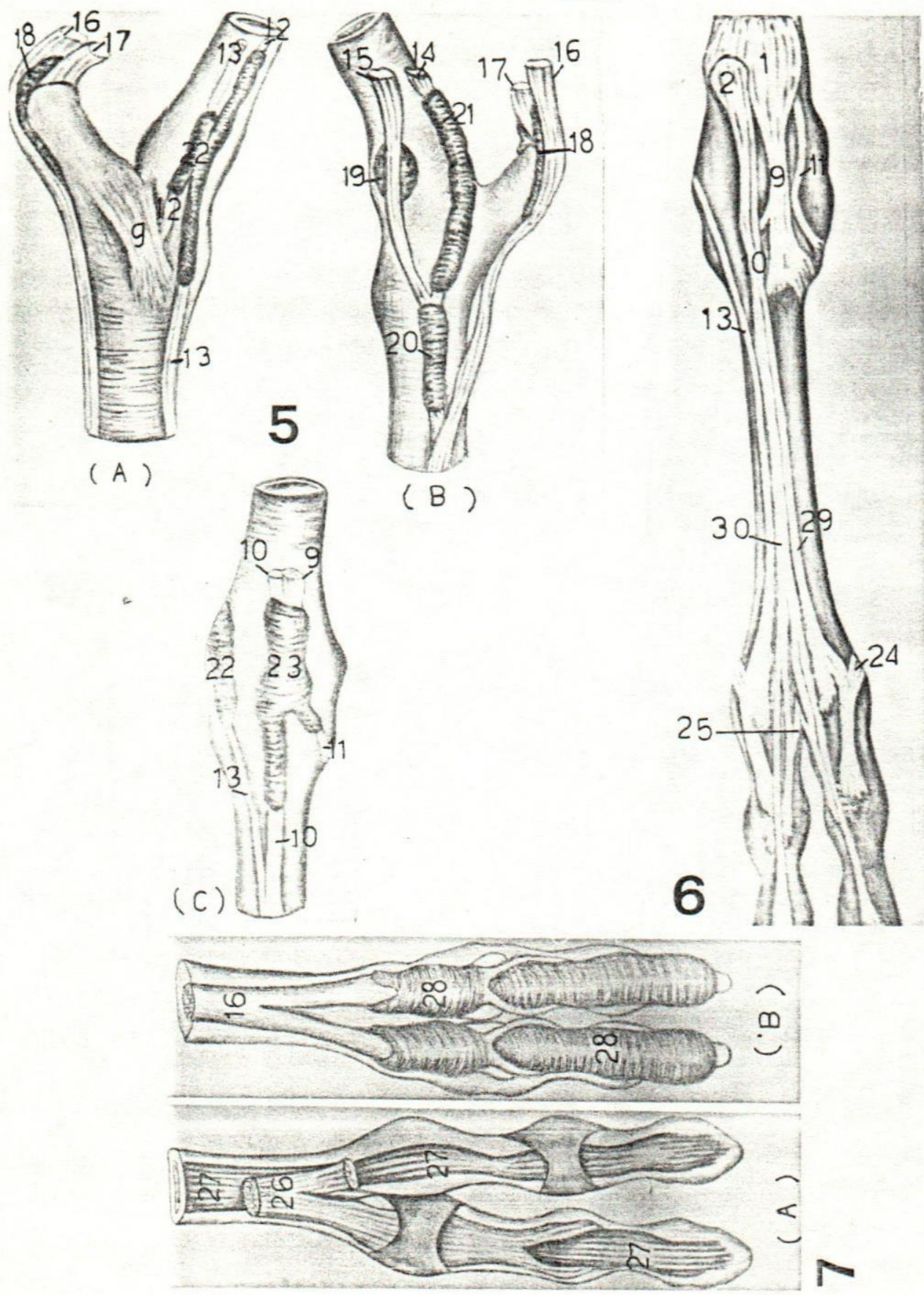

Assiut Vet.Med.J., Voi. 26, No. 51, October 1991. 